\title{
Do intestinal parasitic infestations in patients with clinically acute appendicitis increase the rate of negative laparotomy? Analysis of 3863 cases from Turkey
}

\author{
Enver Ilhan ${ }^{1}$, Abdullah Senlikci $^{1}$, Hale Kızanoglu², Mehmet Akif Ustüner ${ }^{1}$, Enver Vardar ${ }^{2}$, Ahmet Aykas ${ }^{1}$, \\ Eyup Yeldan ${ }^{1}$, Mehmet Yıldırım ${ }^{1}$ \\ ${ }^{1}$ Department of Surgery, Izmir Bozyaka Education and Research Hospital, Izmir, Turkey \\ 2Department of Pathology, Izmir Bozyaka Education and Research Hospital, Izmir, Turkey
}

Prz Gastroenterol 2013; 8 (6): 366-369 DOI: $10.5114 / p g .2013 .39919$

Key words: acute appendicitis, negative laparotomy, parasites, infestation.

Address for correspondence: Dr. Enver Ilhan, Department of Surgery, Izmir Bozyaka Education and Research Hospital, Esenepe Mah. 49 Sokak no 8 Daire 22, Karabağlar, 35350 Izmir, Turkey, phone: +90 5322539565, fax: +90 2322614444, e-mail: enverhan60@gmail.com

\begin{abstract}
Introduction: Acute appendicitis is the most frequently observed disease requiring emergency surgery. The role of parasites in its pathogenesis has long been discussed. The signs of the parasitic infestations can mimic the signs of acute appendicitis. Therefore, it can cause a negative laparotomy.

Aim: To evaluate the parasitic infestations of the appendix vermiformis whether increas the rate of negative laparotomy.

Material and methods: The histopathology results of a total of 3863 patients who underwent appendectomy with clinically acute appendicitis were evaluated retrospectively. All appendectomy materials in which parasites were observed were evaluated with respect to the nature of the parasites and the findings of inflammation. Cases in which parasite tissue fragments and/or eggs as well as findings of inflammation were histopathologically observed in the appendix lumen were diagnosed with parasitic appendicitis.

Results: Evidence of parasites was observed in $19(0.49 \%)$ of the evaluated appendectomy materials. In $9(47.3 \%)$ of these specimens that had evidence for parasites, findings for acute appendicitis and localized peritonitis were identified. Findings of acute appendicitis had not been identified in the other ten (52.7\%) of the specimens. Enterobius vermicularis was the most frequently identified parasite.

Conclusions: In parasitic acute appendicitis, appendectomy in itself is not sufficient for treatment. Pharmacological treatment should also be administered after surgery. Patients should be evaluated prior to surgery for parasites, and diagnosis of acute appendicitis should be considered more cautiously in order to avoid negative laparotomies.
\end{abstract}

\section{Introduction}

The aetiology of acute appendicitis includes fecaliths, lymphoid hyperplasia, fruit and vegetable seeds, barium enemas and tumours. Parasites are one of the more uncommon causes of acute appendicitis. Enterobius vermicularis, Ascaris lumbricoides, Schistosoma spp. and Taenia spp. are the parasites that can lead to a clinical picture of acute appendicitis. Enterobius vermicularis is the parasite that most frequently contributes to a clinical picture of acute appendicitis [1, 2].

\section{Material and methods}

The files and electronic records of 3863 patients who underwent appendectomy at the Izmir Education and Research Hospital General Surgery Clinic between 2003 and 2012 were evaluated retrospectively. All appendectomy materials in which parasites were observed were evaluated with respect to the nature of the parasites and the findings of inflammation.

The appendectomy materials were subject to fixation with $10 \%$ formaldehyde, tissue follow-up and paraffin block embedding. The 4-micron-thick sections obtained from the paraffin blocks were stained with haematoxylin and eosin, and examined under a white light microscope. Cases in which parasite tissue fragments and/ or eggs as well as findings of inflammation were histopathologically observed in the appendix lumen were diagnosed with parasitic appendicitis (Figures 1 and 2). 


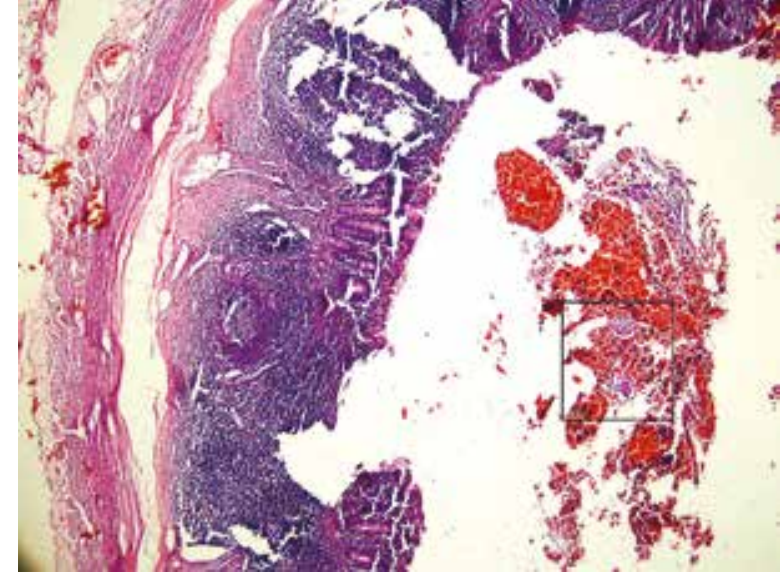

Figure 1. Full thickness of appendiceal wall and two parasites located in black-lined box were seen in the lumina of the appendix $(40 \times \mathrm{H}+\mathrm{E})$

\section{Results}

A total of 3863 patients underwent surgery with clinically acute appendicitis. Parasites had been observed in 19 (0.49\%) of all evaluated appendectomy materials. Of the patients with parasites in their materials, 12 (63.2\%) were female and 7 (36.8\%) were male. Their average age was 30.6 years (range: $17-83$ years). Of these parasites, 16 (84.2\%) were identified as E. vermicularis, and 3 (15.8\%) were identified as Taenia saginata. Acute appendicitis and localized peritonitis had been identified pathologically in 9 (47.3\%) out of a total of 19 appendectomy materials. Findings of acute appendicitis had not been identified in the other ten (52.7\%) materials (Table I). None of the patients had developed any significant morbidity or mortality. All patients had been postoperatively started on anti-parasite treatment and discharged from the hospital between their $1^{\text {st }}$ and $3^{\text {rd }}$ postoperative days.

\section{Discussion}

Acute appendicitis is the most frequently observed disease requiring emergency surgery, and it affects nearly $7 \%$ of the population. It is observed more frequently in developed countries than in developing countries. The main cause of acute appendicitis is the obstruction of the appendix lumen. The underlying cause for its greater frequency in developed countries can hence be explained by hard stools, intracolonic pressure and fecalith formation, which are caused by diet. The obstruction of the appendix causes an increase in intraluminal pressure, leading to mucosal ischaemia. In conjunction with vascular congestion, the appendix mucosa becomes hypoxic and ulcers begin to form. This

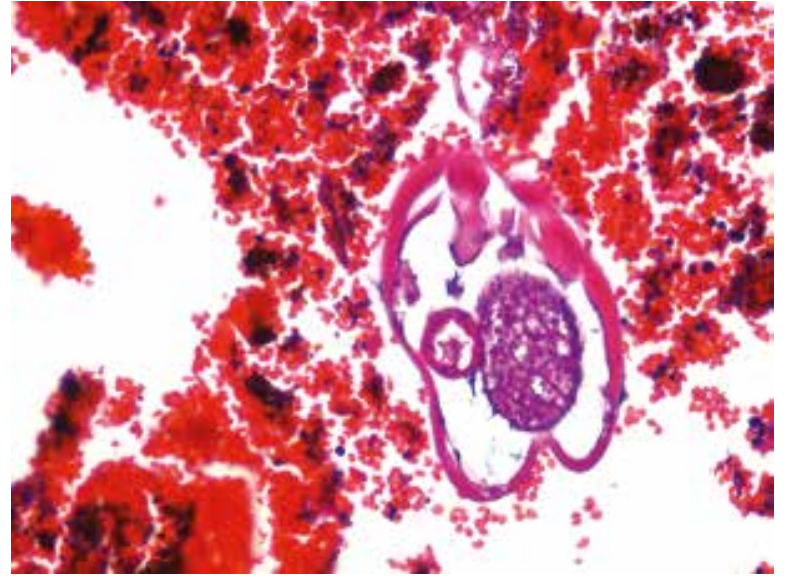

Figure 2. Cut-section of the intestine of the parasite was seenin high-power magnification of the lumina of the appendix $(400 \times \mathrm{H}+\mathrm{E})$

Table I. Demographic parameters and histological findings of the patients

\begin{tabular}{|c|c|c|c|c|c|}
\hline $\begin{array}{l}\text { No. } \\
\text { of } \\
\text { case }\end{array}$ & Gender & Age & Species of parasite & $\begin{array}{l}\text { Acute } \\
\text { inflam- } \\
\text { mation }\end{array}$ & $\begin{array}{c}\text { Negative } \\
\text { laparo- } \\
\text { tomy }\end{array}$ \\
\hline 1 & Female & 29 & Enterobius vermicularis & No & Yes \\
\hline 2 & Female & 40 & Enterobius vermicularis & No & Yes \\
\hline 3 & Female & 18 & Enterobius vermicularis & No & Yes \\
\hline 4 & Female & 33 & Enterobius vermicularis & Yes & No \\
\hline 5 & Female & 25 & Enterobius vermicularis & Yes & No \\
\hline 6 & Female & 19 & Enterobius vermicularis & No & Yes \\
\hline 7 & Male & 33 & Enterobius vermicularis & No & Yes \\
\hline 8 & Male & 17 & Enterobius vermicularis & No & Yes \\
\hline 9 & Female & 29 & Enterobius vermicularis & Yes & No \\
\hline 10 & Male & 30 & Enterobius vermicularis & No & Yes \\
\hline 11 & Female & 33 & Enterobius vermicularis & Yes & No \\
\hline 12 & Female & 24 & Enterobius & No & Yes \\
\hline 13 & Female & 32 & Taenia saginata & No & Yes \\
\hline 14 & Female & 27 & Taenia saginata & Yes & No \\
\hline 15 & Male & 83 & Taenia saginata & Yes & No \\
\hline 16 & Female & 23 & Enterobius vermicularis & Yes & No \\
\hline 17 & Male & 27 & Enterobius vermicularis & Yes & No \\
\hline 18 & Male & 19 & Enterobius vermicularis & No & Yes \\
\hline 19 & Female & 41 & Enterobius vermicularis & Yes & No \\
\hline
\end{tabular}

in turn leads to the invasion of the appendix wall by intraluminal bacteria [3, 4].

Parasitosis is asignificant health problem in endemic countries. Although parasitic diseases are mainly observed in tropical countries, they have also started to become a significant health problem in developing countries due to increasing migration and travel [5]. 
Enterobius vermicularis, Ascaris lumbricoides, Schistosoma spp. and Taenia spp. are among the parasites that lead to aclinical picture of acute appendicitis. The gastrointestinal infections associated with E. vermicularis are the most frequently encountered helmintic infections worldwide $[1,6]$. Although it can be observed in all ages and across all socioeconomic levels, it is seen more frequently among children and the young. The infections are generally asymptomatic in children, and the most commonly observed symptom is itching around the anus. Moreover, E. vermicularis infections may cause ileocolitis, enterocutaneous fistulas, urinary tract infections, mesenteric abscesses, salpengitis and appendicitis. The mature form of $E$. vermicularis is most frequently observed in the proximal section of the ascending colon, the cecum, the appendix and the terminal ileum [7, 8].The relationship between $E$. vermicularis and acute appendicitis was first discovered towards the end of the $19^{\text {th }}$ century $[9,10]$. It has been observed that E. vermicularis can cause pathological changes to the appendix, ranging from lymphoid hyperplasia to acute phlegmonous appendicitis, gangrenous appendicitis and peritonitis [1]. Appendectomy is not sufficient in itself for treatment since it is not able to resolve the main cause of the disease. To obtain the best treatment results, antihelmintic treatment should be provided following surgery [11].

Teniasis, on the other hand, is a well-known tapeworm infection characterized by the presence of Taenia saginata or Taenia solium in the human intestines. Infection generally occurs as a result of consuming raw or undercooked meat [12]. Teniasis may sporadically lead to a clinical picture of acute or subacute appendicitis or cholangitis. A clinical picture of acute appendicitis occurring in association with Taenia is a very uncommon condition [13]. In the event that Taenia is the cause of acute appendicitis, albendazole treatment is provided to the patient following surgery [12].
The identification of intraluminal parasites in appendix material is usually an accidental finding. Such findings are generally observed concomitantly with an appendix that does not display any signs of inflammation. However, the parasitic invasion of the appendix may lead to the clinical symptoms of acute appendicitis, causing colic-like repetitive pain in the right lower quadrant. As a parasitic infection is actually present within the intestinal system, the clinical and laboratory findings will be suggestive of an infection. However, acute appendicitis will not be histologically present [5]. In our study, acute appendicitis and localized peritonitis were observed in 9 (47.3\%) out of a total of 19 materials. The remaining ten $(52.7 \% \%)$ materials did not demonstrate any findings of acute appendicitis, and the laparotomies that had been performed were hence considered as negative laparotomies.

In a study presented by Engin et al. in Turkey, parasites were observed in 9/1969 (0.45\%) appendectomy materials [3]. In a study presented by Karatepe et al. in Turkey, parasites were observed in 24/5100 (0.5\%) appendectomy materials, and the rate of no inflammation with appendix specimen was determined as $6 / 24$ (25\%) [4]. Similarly, Aydın 6/190 (3.15\%) and 4/6 (66.6\%) [5], Da Silva et al. 24/1600 (1.5\%) and 12/24 (50\%) [1], Sah and Bhadani 9/624 (1.62\%) and 6/9 (66.6\%) [14], Gialamas et al. 7/1085 (0.64\%) and 6/7 (85.7\%) [7], and Ramezani and Dehghani 144/5048 (2.9\%) and 68/144 (47.2\%) [15] reported the rates, respectively (Table II).

The identification of parasites in $19 / 3863$ (0.49\%) of the appendix materials of cases operated with a clinically acute appendicitis in our study was consistent with the literature.

As can be seen in the literature and in our study, the rate of absence of acute inflammation in patients operated with a clinically acute appendicitis and having parasites in their appendix lumen is very high. This is indicative of the high rate of negative laparotomy that has been performed on these patients.

Table II. Data obtained from countries included in this study

\begin{tabular}{|c|c|c|c|c|c|}
\hline \multirow[t]{2}{*}{ Author } & \multirow[t]{2}{*}{ Country } & \multirow[t]{2}{*}{ Total materials, $n$} & \multicolumn{3}{|c|}{ Materials with parasites } \\
\hline & & & $\begin{array}{l}\text { Total, } \\
n(\%)\end{array}$ & $\begin{array}{c}\text { Acute } \\
\text { inflammation, } n \%\end{array}$ & $\begin{array}{c}\text { No acute } \\
\text { inflammation, } n(\%)\end{array}$ \\
\hline Ramezani et al. & Iran & 5048 & $144(2.9)$ & $76(52.8)$ & $68(47.2)$ \\
\hline Karatepe et al. & Turkey & 5100 & $24(0.5)$ & $18(75)$ & $6(25)$ \\
\hline Aydın et al. & Turkey & 190 & $6(3.15)$ & $2(33.3)$ & $4(66.7)$ \\
\hline De Silva et al. & Brazil & 1600 & $24(1.5)$ & $12(50)$ & $12(50)$ \\
\hline Sah et al. & Nepal & 624 & $9(1.62)$ & $3(33.3)$ & $6(66.7)$ \\
\hline Gialamas et al. & Greece & 1085 & $7(0.64)$ & $1(14.3)$ & $6(85.7)$ \\
\hline Current study & Turkey & 3863 & $19(0.49)$ & $9(47.4)$ & $10(52.6)$ \\
\hline
\end{tabular}


In conclusion, E. vermicularis is the most frequently found parasite in the appendix lumen of patients operated with a clinically acute appendicitis. In cases where parasites are present in the appendix lumen, the rate of negative laparotomy becomes higher. In order to avoid the surgical side effects associated with negative laparotomy, patients applying for complaints of abdominal pain should be examined also for intestinal parasites. Patients whose medical history as well as clinical and laboratory findings are positive should be considered and evaluated more carefully. In addition to this, patients with acute appendicitis caused by parasites should receive anti-parasitic treatment following surgery.

\section{References}

1. de Silva DF, da Silva RJ, da Silva MG, et al. Parasitic infection of the appendix as a cause of acute appendicitis. Parasitol Res 2007; 102: 99-102.

2. Pasupati TM, Yothasamutr K, Wah MJ, et al. A study of parasitic infections in the luminal contents and tissue sections of appendix specimens. Tropical Biomedicine 2008; 25: 166-72.

3. Engin O, Calik S, Calik B, et al. Parasitic appendicitis from past to present in Turkey. Iran J Parasitol 2010; 5: 57-63.

4. Karatepe O, Adas G, Tukenmez M, et al. Parasitic infestation as cause of acute appendicitis. G Chir 2009; 30: 426-8.

5. Aydın 0 . Incidental parasitic infestations in surgically removed appendices: a retrospective analysis. Diagnost Pathol 2007; 2: 16.

6. Kazemzadeh H, Afshar-Moghadam N, Meamar AR, et al. Enterobious vermicularis and the Appendix: report of five cases. Iran J Parasitol 2008; 3: 54-5.

7. Gialamas E, Papavramidis T, Michalopoulos, et al. Enterobius vermicularis: a rare cause of appendicitis. Turkiye Parazitol Derg 2012; 36: 37-40.

8. Sodergren MH, Jethwa P, Wilkinson S, et al. Presenting features of Enterobius vermicularis in the vermiform appendix. Scand J Gastroenterol 2009; 44: 457-61.

9. Stil GF. Oxyuriasis vermicularis in children. Br Med J 1899; 1: 898-900.

10. Fry FG, Morre JG. Enterobius vermicularis, 10,000-year-old human infection. Science 1969; 166: 1620.

11. Nackley AC, Nackley JJ, Yeko TR, et al. Appendiceal enterobius vermicularis infestation associated with right-sided chronic pelvic pain. JSLS 2004; 8: 171-3.

12. Sartorelli AC, da Silva MG, Rodrigues MAM, et al. Appendiceal taeniasis presenting like acute appendicitis. Parasitol Res 2005; 97: 171-2.

13. Kia EB, Afshar-Moghadam N, Kazemzade H. Appendicular taeniasis: association with acute gangrene appendicitis in Isfahan, Iran. South Asian J Trop Med Public Health 2004; 35: 259-61.

14. Sah SP, Bhadani PP. Enterobius vermicularis causing symptoms of appendicitis in Nepal. Trop Doct 2006; 36: 160-2.

15. Ramezani MA, Dehghani MR. Relationship between Enterobius vermicularis and the incidence of acute appendicitis. Southeast Asian J Trop Med Public Health 2007; 38: 20-3.

Received: 13.02 .2013

Accepted: 28.03 .2013 